\title{
Застосування доплерівської флоуметрії як способу оцінки васкуляризації патологічних післяопераційних рубців шкіри обличчя
}

\begin{abstract}
Мета роботи: вивчення застосування доплерівської флоуметрії як діагностичного методу для оцінки комбінованого методу профілактики утворення патологічних рубців шкіри обличчя.

Матеріали і методи. Роботу виконано на базі відділення ЩЛХ Львівської ОКЛ. Обстежено 25 пацієнтів, які в подальшому були розподілені на 2 групи. До групи порівняння $(\mathrm{n}=10)$ включено хворих, в яких рани загоювалися первинним натягом та не проводили жодних профілактичних процедур. До основної групи $(\mathrm{n}=15)$ входили пацієнти, в яких рани гоїлися первинним натягом та застосовували комбінацію сеансів ЕУХТ та аплікацій силіконового гелю “Стратадерм”.

Результати досліджень та їх обговорення. При контрольній доплерографії післяопераційних рубців у пацієнтів групи порівняння візуалізуються поодинокі локуси кровопостачання довкола рубця, ознак набряку чи запальної інфільтрації не виявлено.

При контрольній доплерівській флоуметрії післяопераційних рубців у пацієнтів основної групи виявлено виражені локуси кровопостачання різної інтенсивності з наявністю живильних судинних структур по всій площі обстежуваної ділянки.
\end{abstract}

Ключові слова: післяопераційні патологічні рубці; екстракорпоральна ударно-хвильова терапія; силіконовий гель; доплерівська флоуметрія.

Постановка проблеми і аналіз останніх досліджень та публікацій. Доплерографія - це методика ультразвукового дослідження кровообігу, яка дозволяє отримати інформацію про стан судин і швидкість кровотоку в режимі реального часу. Доплерівську флоуметрію застосовують як метод діагностики стану кровотоку на капілярному рівні, який здійснює безпосередній вплив на метаболічні процеси в органах і тканинах. В основі методу лежить вимірювання доплерівської компоненти в спектрі відбитого лазерного сигналу. Створюється двовимірне кольорове зображення, що дає унікальну можливість оцінити величину тканинної перфузії, тобто обсягу крові, що протікає в поверхневих шарах шкіри.

Запропоновано використовувати показники доплерівської флоуметрії для оцінки впливу комплексної профілактики на перебіг неоангіогенезу та рівня васкуляризації у післяопераційних рубцях шкіри обличчя $[1,2,3,4,8]$.

Мета роботи: вивчення застосування доплерівської флоуметрії як діагностичного методу для оцінки комбінованого методу профілактики утворення патологічних рубців шкіри обличчя.

Матеріали і методи. Наукову роботу виконано на базі відділення ЩЛХ ЛОКЛ. Обстежено 25 пацієнтів, яким застосували зовнішньоротові доступи при проведенні оперативних втручань. Всі операції були проведені під комбінованим знеболенням.

У подальшому усі пацієнти були розподілені на дві групи. Пацієнтів розподіляли на групи без певної закономірності у випадковому порядку.
До групи порівняння (n=10) включено хворих, в яких загоєння рани відбувалося первинним натягом та не проводилося жодних профілактичних процедур. До основної групи (n=15) входили пацієнти, в яких загоєння рани відбувалося первинним натягом та застосовувалася комбінація сеансів екстракорпоральної ударно-хвильової терапії та аплікацій силіконового гелю “Стратадерм”. Розподіл пацієнтів по групах проводився без певної закономірності у випадковому порядку. Профілактичні заходи розпочинали проводити з моменту зняття швів [5, 7].

Сеанси екстракорпоральної ударно-хвильової терапії проводили швейцарським апаратом Storz Medical Master Plus MP100 [6]. Місцеве знеболення при виконанні процедур не застосовували (рис. 1).

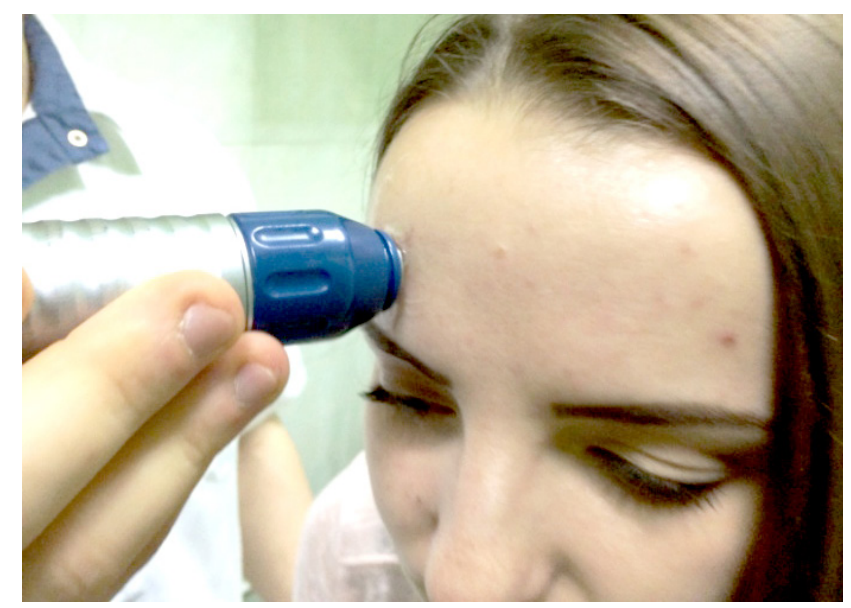

Рис. 1. Проведення сеансу екстракорпоральної ударно-хвильової терапії. 
Силіконовий гель “Стратадерм” (виробник: STRATPHARMA AG (Switzerland) наносився тонким шаром на рубець і утворював на ньому тонку плівку після висихання.

Доплерографію проводили в комплексі з ультразвуковим обстеженням. Проводили дослідження периферичної гемодинаміки післяопераційних рубців шкіри обличчя методом ультразвукової доплерографії на ультразвуковому діагностичному приладі Toshiba Aplio XV за допомогою високочастотного датчика частотою 9-14 МГц перед початком проведення першої процедури ЕУХТ та контрольне обстеження через шість місяців після завершення профілактики.

Результати досліджень та їх обговорення. Оцінка та порівняння даних доплерівського сканування післяопераційних рубців встановили, що збільшення кровопостачання тканин - це прояв компенсаторних реакцій тканин на їх метаболічний запит і кисневі потреби.

При доплерографії післяопераційного рубця, проведеної після зняття швів у пацієнта, що належав до групи порівняння, ознак посиленої васкуляризації не виявлено. Судинних структур не виявлено (рис. 2).

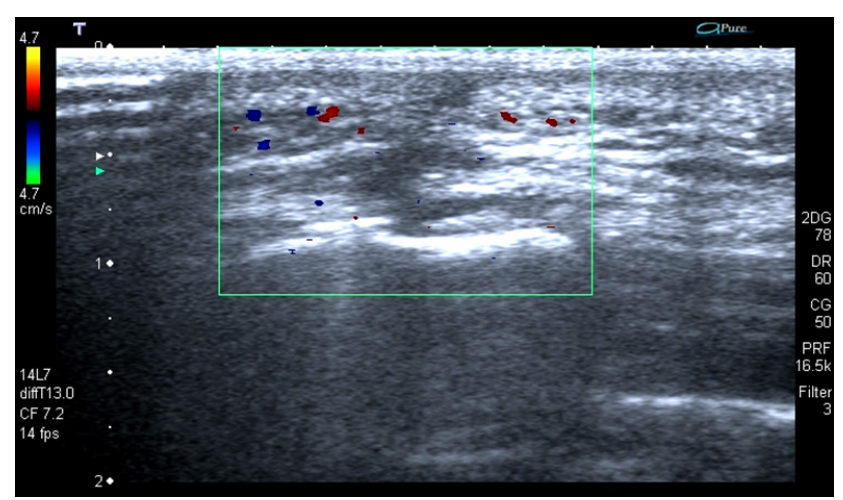

Рис. 2. Сонографія післяопераційного рубця пацієнта Ю., 34 роки. Кольорова доплерографія. Група порівняння.

При контрольній доплерографії післяопераційного рубця у пацієнта, що належав до групи порівняння, яка проведена через 6 місяців після загоєння рани, візуалізуються поодинокі локуси кровопостачання довкола рубця, ознак набряку чи запальної інфільтрації не виявлено (рис. 3).

Доплерівську флоуметрію післяопераційного рубця проведено після зняття швів у пацієнта основної групи, не виявила виражених судинних структур. Васкуляризація ділянки не значна. Локуси кровопостачання майже відсутні (рис. 4).
При контрольній доплерівській флоуметрії післяопераційного рубця у пацієнта основної групи через 6 місяців виявлено виражені локуси кровопостачання різної інтенсивності 3 наявністю живильних судинних структур по всій площі обстежуваної ділянки (рис. 5).

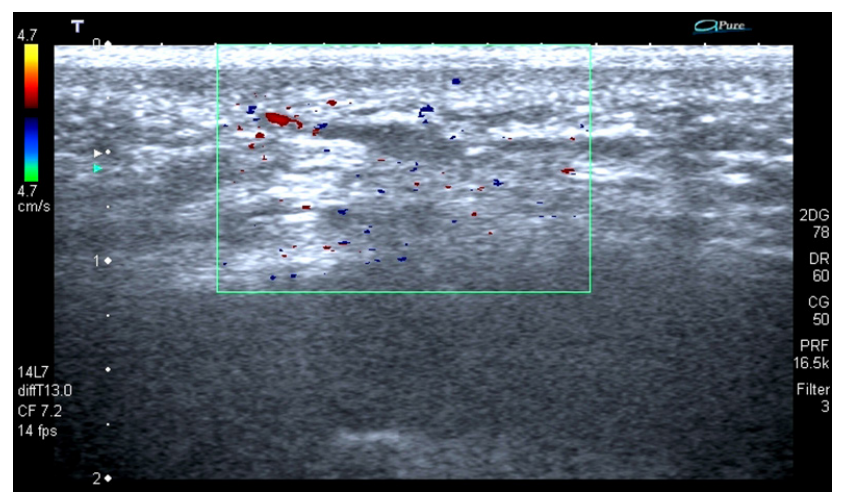

Рис. 3. Контрольна сонографія післяопераційного рубця пацієнта Ю., 34 роки. Кольорова доплерографія через 6 місяців. Група порівняння.

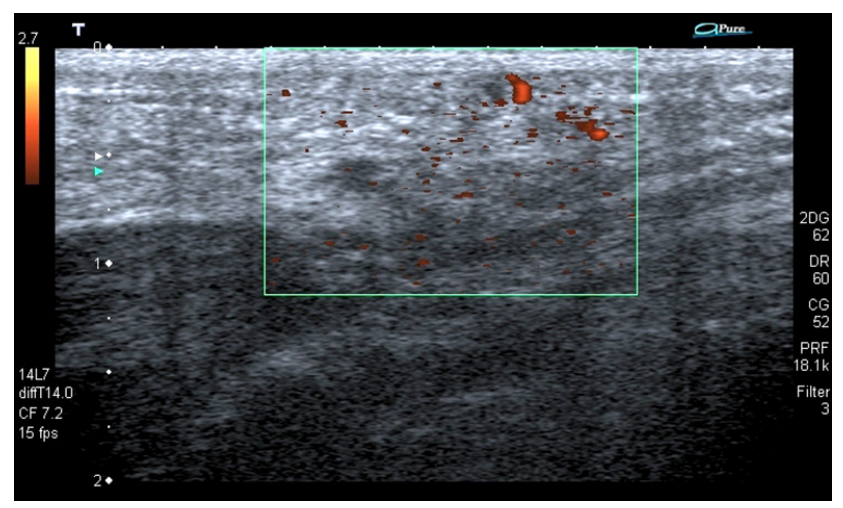

Рис. 4. Сонографія післяопераційного рубця пацієнта В., 22 роки. Кольорова доплерографія. Основна група.

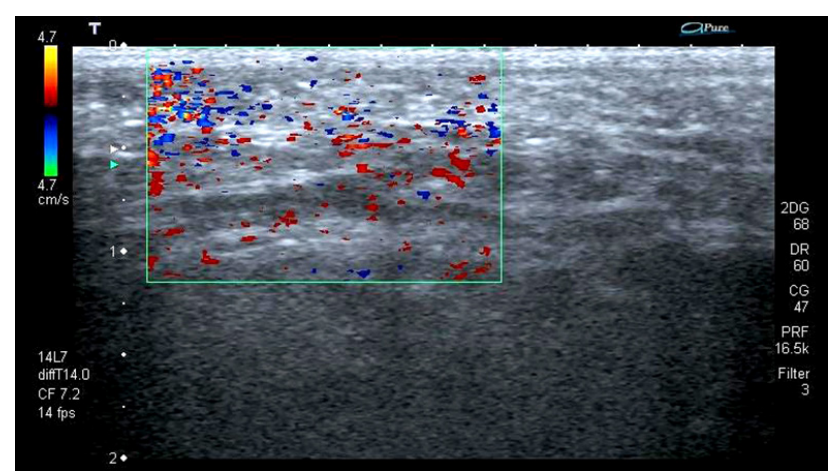

Рис. 5. Контрольна сонографія післяопераційного рубця пацієнта В., 22 роки. Кольорова доплерографія через 6 місяців. Основна група. 


\section{СПИСОК ЛІТЕРАТУРИ}

1. Фисталь Н. Н. Лазерная допплеровская флоуметрия при лечении ожогов / Н. Н. Фисталь, В. В. Солошенко // Хирургия. - 2008. - № 11. - С. 53-57.

2. A comparative study of colour and perfusion between two different post surgical scars. Do the laser Dopplerimager and the colorimeter measure the same features of a scar? / J. F. Mermans, W. J. Peeters, R. Dikmans [et al.] // Skin. Res. Technol. - 2013. Vol. 19, No. 2 - P. 107-114.

3. Can single use negative pressure wound therapy be an alternative method to manage keloid scarring? A preliminary report of a clinical and ultrasound/colour-power-doppler study / M. Fraccalvieri, A. Sarno, S. Gasperini [et al.] // Int. Wound J. 2013. - Vol. 10, No. 3. - P. 340-344.

4. Detection of changes of scar thickness under mechanical

\section{REFERENCES}

1. Fistal, N.N., \& Soloshenko, V.V. (2008). Lazernaya dopplerovskaya floumetriya pri lechenii ozhogov [Laser Doppler flowmetry in the treatment of burns]. Kirurgiya - Surgery, 11, 5357 [in Russian].

2. Mermans, J.F., Peeters, W.J., \& Dikmans, R. (2013). A comparative study of colour and perfusion between two different post surgical scars. Do the laser Dopplerimager and the colorimeter measure the same features of a scar? Skin. Res. Technol., 19 (2), 107-114.

3. Fraccalvieri, M., Sarno, A., \& Gasperini, S. (2013). Can single use negative pressure wound therapy be an alternative method to manage keloid scarring? A preliminary report of a clinical and ultrasound/colour-power-doppler study. Int. Wound J., 10 (3), 340-344.

4. Li, J.Q., Li-Tsang, C.W., \& Huang, Y.P. (2013). Detection loading using ultrasonic measurement / J. Q. Li, C. W. Li-Tsang, Y. P. Huang [et al.] // Burns. - 2013. - Vol. 39, No. 1. - P. 89-97. 5. Efficacy and safety of an advanced formula silicone gel for prevention of post-operative scars / B. Medhi, R. K. Sewal, L. Kaman [et al.] // Dermatol. Ther. - 2013. - Vol. 3, No. 2. - P. 157-167.

6. Extracorporeal shock wave therapy for the management of burn scars / P. Fioramonti, E. Cigna, M. G. Onesti [et al.] // Dermatologic. Surgery. - 2012. - Vol. 38, No. 5. - P. 778-782.

7. Téot L. Prevention of pathologic scars / L. Téot // Soins. 2013. - Vol. 58, No. 772. - P. 50.

8. Wang X. Q. Ultrasound assessed thickness of burn scars in association with laser Doppler imaging determined depth of burns in paediatric patients / X. Q. Wang, J. Mill, O. Kravchuk, R. M. Kimble// Burns. - 2010. - Vol.36, No. 8. - P. 1254-1262.

of changes of scar thickness under mechanical loading using ultrasonic measurement. Burns, 39 (1), 89-97.

5. Medhi, B., Sewal, R.K., \& Kaman, L. (2013). Efficacy and safety of an advanced formula silicone gel for prevention of postoperative scars. Dermatol. Ther., 3 (2), 1570167.

6. Fioramonti, P., Cigna, E., \& Onesti, M.G. (2012). Extracorporeal shock wave therapy for the management of burn scars. Dermatologic. Surgery, 38 (5), 778-782.

7. Téot, L. (2013). Prevention of pathologic scars. Soins, 58 (772), 50.

8. Wang, X.Q., Mill, J., Kravchuk, O., \& Kimble, R.M. (2010). Ultrasound assessed thickness of burn scars in association with laser Doppler imaging determined depth of burns in paediatric patients. Burns, 36 (8), 1254-1262.

Отримано 23.07.2018

Електронна адреса для листування: jurmelnichuk@rambler.ru

YU. M. MELNYCHUK, R. Z. OHONOVSKYI, I. YA. LOMNYTSKYI

Danylo Halytskyi Lviv National Medical University

\section{APPLICATION OF DOPPLER FLOWMETRY AS A MEASURE OF ASSESSMENT OF VASCULARIZATION OF PATHOLOGICAL POSTOPERATIVE FACIAL SCARRING}

The aim of the work: to study the application of Doppler flowmetry as a diagnostic method for assessing the combined method of prevention of pathological scar formation in the face of the skin.

Materials and Methods. 25 patients were examined, who were subsequently divided into 2 groups. The comparison group ( $\mathrm{n}=10$ ) included patients in whom wound healing was the primary tension and no prophylactic procedures were performed. The main group (n $=15$ ) included patients in whom wound healing was the primary tension and a combination of shock waves sessions and Strataderm silicone gel application was used.

Results and Discussion. In the control doplerography of postoperative scarring, in patients referring to the comparison group, isolated blood circulatory loci around the scar were visualized, signs of edema or inflammatory infiltration were not detected.

At controlled Doppler flowmetry of postoperative scarring in patients of the main group, expressed blood supply locus of varying intensity with the presence of nutritional vascular structures throughout the area of the examined area.

Key words: postoperative pathological scars; extracorporeal shock wave therapy; silicone gel; Doppler flowmetry. 
Ю. Н. МЕЛЬНИЧУК, Р. З. ОГОНОВСКИЙ, И. Я. ЛОМНИЦКИЙ

Львовский национальный медицинский университет имени Данила Галицкого

ПРИМЕНЕНИЕ ДОППЛЕРОВСКОЙ ФЛОУМЕТРИИ КАК СПОСОБА ДЛЯ ОЦЕНКИ

ВАСКУЛЯРИЗАЦИИ ПАТОЛОГИЧЕСКИХ ПОС.ЕОПЕРАЦИОННЫХ РУБЦОВ КОЖИ ЛИЦА

Цель работы: изучение применения допплеровской флоуметрии как диагностического метода для оценки комбинированного метода профилактики образования патологических рубцов кожи лица.

Материалы и методы. Работу выполнено на базе отделения ЩЛХ Львовской ОКБ. Обследовано 25 пациентов, которые в дальнейшем были разделены на 2 группы. В группу сравнения $(\mathrm{n}=10)$ включены больные, у которых заживление раны происходило первичным натяжением и не проводилось никаких профилактических процедур. В основную группу (n=15) входили пациенты, у которых заживление раны происходило первичным натяжением и применялась комбинация сеансов ЕУХТ и аппликаций силиконового геля “Стратадерм”.

Результаты исследований и их обсуждение. При контрольной допплерографии послеоперационных рубцов у пациентов, которые относились к группе сравнения, визуализируются единичные локусы кровоснабжение вокруг рубца, признаков отека или воспалительной инфильтрации не обнаружено.

При контрольной допплеровской флоуметрии послеоперационных рубцов у пациентов основной группы выявлены выраженные локусы кровоснабжения различной интенсивности с наличием питательных сосудистых структур по всей площади обследуемой области.

Ключевые слова: послеоперационные патологические рубцы; экстракорпоральная ударно-волновая терапия; силиконовый гель; допплеровская флоуметрия. 